\title{
GESTÃO PÚBLICA
}

O campo da gestão pública é marcado hoje por uma grande variedade de temas e abordagens, incluindo desde governança global até gestão local, passando pela reforma do Estado e pela redefinição das relações que as diversas instâncias de governo e os atores sociais mantêm na esfera pública. De caráter interdisciplinar, a gestão pública tem como desafio consolidar as contribuições das diversas áreas do saber que também se ocupam dos mesmos objetos de estudo. Seus objetivos são, ao mesmo tempo, políticos, gerenciais e científicos, contribuindo para o aprofundamento da democracia e o desenvolvimento do campo como área de conhecimento legítima. Levando-se em conta esses aspectos, a doutoranda Paula Chies Schommer, da FGV-EAESP, indica livros cuja leitura contribuirá para a compreensão de desafios, potencialidades e perspectivas no campo da gestão pública no Brasil e no mundo.
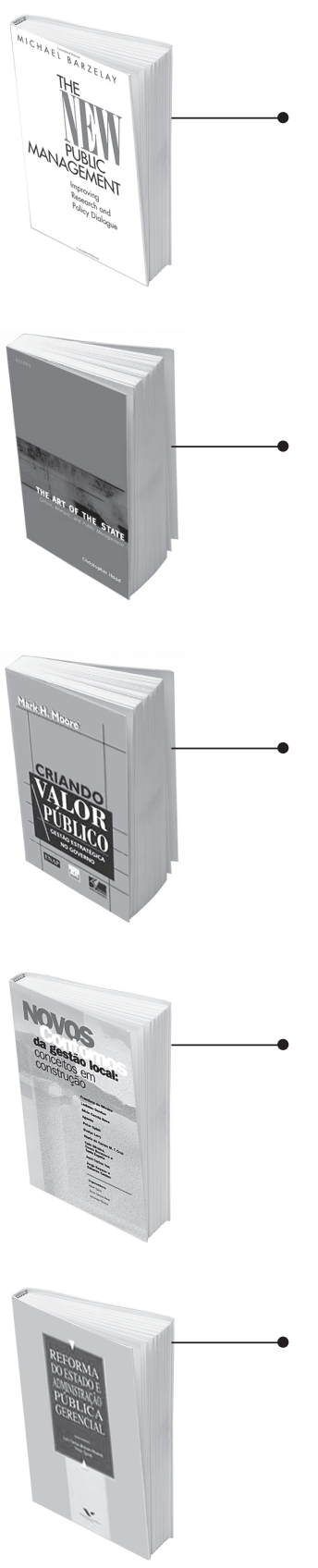

THE NEW PUBLIC MANAGEMENT: improving research and policy dialogue Michael Barzelay. Berkeley: University of California Press, 2001. 240 p.

Este livro tem sido reconhecido como um consistente trabalho que busca fazer a relação entre teoria e prática em gestão pública. Promove uma aproximação entre pesquisa e formulação de políticas, baseando-se em uma perspectiva interdisciplinar. Consolida visões e debates inseridos na corrente do new public management, termo usado para definir um conjunto de temas, estilos e padrões de gestão dos serviços públicos, com exemplos da Austrália, da Nova Zelândia, do Reino Unido, entre outros.

THE ART OF THE STATE: culture, rhetoric, and public management Christopher Hood. Oxford: Clarendon Press, 2. ed., 2000. $320 \mathrm{p}$.

O livro baseia-se em uma abordagem culturalista para analisar diversos modelos de administração pública e as teorias implicadas nesses modelos. Por meio de uma crítica aos modismos e às abordagens "globalizantes", sugere que a variedade de formas de organização dos serviços públicos não deve desaparecer. Para defender esse argumento, faz uma revisão bastante atualizada da literatura, trazendo discussões sobre teoria da escolha racional, teoria burocrática "clássica", novo institucionalismo, entre outras.

CRIANDO VALOR PÚBLICO: gestão estratégica no governo Mark H. Moore. Rio de Janeiro: Letras \& Expressões/ Brasília: Enap, 2002. 560 p.

O livro oferece um referencial para que gestores públicos possam refletir a respeito de suas próprias práticas. Ao estabelecer conexões entre o estudo dos fins das políticas públicas e dos meios da administração pública, explora a questão de como os gestores podem criar valor público diante de políticas instáveis e em cenários em constante transformação. A partir de uma série de casos, inclusive do setor privado, instiga o leitor a rever, melhorar e até mesmo a desafiar novas práticas na administração pública.

NOVOS CONTORNOS DA GESTÃo LOCAL: conceitos em construção Peter Spink, Silvio Caccia-Bava e Verônica Paulics (Orgs.). São Paulo: Instituto Pólis e Programa Gestão Pública e Cidadania, 2002. 336 p.

Esta coletânea é um marco para quem tem, como foco, a gestão local e a democracia. Reúne reflexões de autores que buscam contribuir para a formulação de novos conceitos em gestão pública, partindo de experiências concretas de inovação empreendidas pelos governos locais no Brasil. Com base em uma noção ampliada de espaço público, os autores analisam as condições para que essas inovações se desenvolvam e se disseminem, trazendo respostas consistentes aos atuais desafios da gestão pública.

REFORMA DO ESTADO E ADMINISTRAÇÃO PÚBLICA GERENCIAL Luiz Carlos Bresser-Pereira e Peter Spink (Orgs.). Rio de Janeiro: FGV, 2. ed., 1998. 316 p.

Livro que reúne contribuições de pesquisadores brasileiros e estrangeiros e de gestores envolvidos em processos de reforma. Uma das idéias centrais é a necessidade de repensar e reconstruir o Estado e não reduzi-lo ao mínimo. A abordagem gerencial é apontada como uma alternativa à perspectiva centrada na burocracia. Destaca-se que o campo está em constante transformação, e que os processos de reforma do Estado, em especial na América Latina, são complexos, marcados por idas e vindas e contradições. 